\title{
Seminário em homenagem ao professor Emanuel Bouzon
}

Giselle Marques Camara

\section{Maat: O princípio ordenador do cosmos egípcio}

A dimensão do simbolismo expressado pelo que a intelectualidade moderna convencionou designar como "a deusa maat" do Antigo Egito Faraônico será dificilmente traduzida em breves palavras desse pretensioso ensaio. Seu simbolismo constitui um dos alicerces fundamentais para a construção de uma sólida reflexão sobre o pensamento e a estruturação social do povo que se enraizou durante milênios em ambas as margens de quase toda a extensão do rio Nilo. A "deusa" Maat, ao contrário de seus "deuses-irmãos" que encerram atributos específicos, é dificilmente traduzida, pois além de ser descrita como um princípio inerente à criação cósmica, permeia tudo o que está contido no universo, tal como os egípcios o compreendiam. Partiremos, então, de um entendimento comum entre os egiptólogos modernos, o de que a deusa encerra em si o princípio da justiça e da verdade absolutas, e acima de tudo, o princípio da própria ordenação e, portanto, condição de existência de todo o cosmos.

É inevitável tomar um dos mais recorrentes e importantes mitos criacionistas como ponto de partida para a compreensão da divindade aqui em questão. $\mathrm{O}$ foco de análise recai sobre os textos referentes à cosmogonia de um dos mais tradicionais, quiçá o mais antigo, centro religioso do Império Faraônico, assentado na cidade de nome grego Heliópolis, e de nome 
egipcíaco Iиnnu, localizado atualmente ao norte do Cairo, no Baixo Egito1. Vale ressaltar que, as denominadas Escolas de Mistério do Antigo Egito eram grandes centros de produção de conhecimento teológico sem, no entanto, se prestarem à função de centros normatizadores de pretensas "concepções religiosas universais". Ou seja, os mitos da criação variavam de escola para escola, ainda que alguns fossem mais destacados pela Antiguidade e tradição do seu clero, como a escola de Heliópolis (2780 2300 a.C.), por exemplo. Não existiam textos oficiais, porém apesar da enorme heterogeneidade das práticas míticas e ritualísticas, tais manifestações religiosas sempre se remetiam a questões que convergiam para estruturas míticas elementares, que conferiam um caráter específico ao pensamento mitológico do Antigo Egito ${ }^{2}$.

A primeira questão a se colocar, trata-se de um resumido entendimento do movimento inicial da criação cósmica egípcia, onde a divindade em questão, que aparece primeiramente referida na cosmogonia não propriamente como uma deusa, mas como um atributo da deusa Tefnut (integrante do primeiro par divino surgido no cosmos), já assume a significação de ordem (maat). Foi somente a partir da Terceira Dinastia faraônica, que Tefnut passa a ser sincretizada com o seu próprio atributo, que assume a forma da deusa Maat, e passa a ocupar, a partir de então, um lugar privilegiado tanto nas mais altas práticas ritualísticas sacerdotais, como nas práticas sociais cotidianamente presentes na vida dos homens egípcios. Comecemos, então.

Segundo a concepção criacionistas dos antigos egípcios, antes do desenvolvimento de um cosmos estruturado, existia um oceano ilimitado de água inerte, imerso em trevas. Esse oceano era considerado uma entidade que precedia a todos os deuses, e a todas as coisas posteriormente criadas. Tal entidade designava-se por Num. Nunca foram construídos templos para essa entidade primeva, mas ela encontrava-se presente em todos eles: nos

\footnotetext{
1 A terminologia Alto e Baixo Egito tivera sua origem no Antigo Egito, dividido territorialmente em dois reinos: o do norte compreendia todo o Delta do Nilo, e o do sul as terras que se localizavam logo abaixo dele e se estendiam até os limites de fronteira ao sul.

${ }^{2}$ Os textos aqui referidos tratam-se dos Textos das Pirâmides, descobertos em 1881, registrados nas paredes de pedra que compõe não só as câmaras mortuárias, mas também, as salas adjacentes a estas, de cinco pirâmides, em Sakkara (necrópole que se localiza ao sul do Cairo): as de Unas - último faraó da V Dinastia, Teti, Pepi I, Merenrê e Pepi II - todos da IV Dinastia (ambas com mais ou menos 2500 a.C.). Tais textos descrevem, minuciosamente, o ato da criação, bem como a trajetória humana, rumo à reincorporação com o seu centro criador.
} 
lagos sagrados dos templos que simbolizavam a "não-existência", o estado de latência antes da criação.

No princípio, o deus Atum, considerado o "pai dos deuses", o "completo", "a residência do universo da luz", estava cercado por essa "densa escuridão infinita" (Nun), manifestando-se como uma bolha de claridade e ordem rodeada pela eterna noite do Oceano Primordial. Atum encontrava-se sozinho no universo, pois inerente a sua natureza, repousavam em estado de latência todos os deuses e deusas, ou seja, todas as energias criativas que só assumem suas formas e atributos no "vir-a-ser". Atum, na visão egípcia, era considerado "a grande mônada", pois toda a existência/diversidade era unidade no princípio, e todo o devir já estava programado de forma planejada e ordenada pelo único criador. Geralmente, os textos referem-se a esse deus no gênero masculino, mas, em realidade, como sintetizava toda a existência, era compreendido como o "grande eleela". Isso porque, como todos os princípios criativos presentes no cosmos egípcio, existiam duas polaridades que se complementavam, uma feminina representada por uma deusa que simbolizava o estado de imutabilidade do cosmos - e uma masculina - representado por um "deus-irmão" que simbolizava as mudanças ocorridas no cosmos. A criação dos deuses só ocorria em pares que se complementavam. Veremos essa questão um pouco mais adiante.

O movimento da criação, portanto, acontece em três etapas: a primeira etapa compreende o estado de latência do cosmos, onde o mundo idealizado por Atum ainda não havia sido criado - "o não-ser"; o segundo movimento, o "vir-a-ser", compreende a primeira etapa da criação, que segundo o mito menfita, ocorreu devido à verbalização das idéias latentes, momento esse, em que Atum rompe com a escuridão do Num. A criação pelo verbo foi, portanto, o local de materialização, de realização e da possibilidade de existência, a ponte entre o "não-ser" (universo latente) e o "ser" (o universo criado); o terceiro, e último movimento foi o "ser", a existência, a criação dos primeiros pares divinos que se encarregaram de criar as condições necessárias para o surgimento da natureza e dos homens.

O primeiro movimento de existência foi a criação dos gêmeos $S h u$ e Tefnut, que representam respectivamente, os atributos da "vida" e da "ordem". A organização básica do universo é, segundo a teologia heliopolitana, uma combinação da vontade de Atum em partilhar de sua essência com a criação desse primeiro par de deuses. Na verdade, tais deuses, já estavam presentes na intenção do Criador, e no momento do vir-aser, se colocam na dianteira do processo de criação. 
Shu simbolizava o "sopro de vida", enquanto Tefnut representava "o lugar de cada coisa no cosmos". Os egiptólogos mais proeminentes encontram grandes dificuldades em estabelecer os atributos da deusa. $\mathrm{O}$ símbolo que a representa é um vaso, provavelmente sugerindo o útero feminino. Parece que os próprios egípcios tiveram dificuldades em transmitir a idéia contida em tal princípio, o que, supostamente possa os ter conduzido à substituição da deusa por seu atributo mais facilmente inteligível - o de ordenação cósmica - substituindo-o, alguns séculos posteriormente, pela deusa Maat.

A etimologia das palavras Tefnut e $S h u$, revela um padrão de complementaridade, pois a formação de sua estrutura silábica (não cabe aqui, discutir de forma aprofundada essa questão, apenas ressaltar um característica que é relevante para o presente estudo) se relaciona com o que os antigos determinavam como sendo palavras que assumem o caráter intrínseco de expressar idéias relacionadas à imutabilidade ou à mudança. Esse caráter inerente às palavras e ao seu lugar ocupado no capital simbólico do antigo Egito - o estático, e o dinâmico - parece nos princípios femininos como as noções de perfectibilidade, completude e imutabilidade. Enquanto as palavras de caráter masculino expressam o movimento da vida como dinâmica e recorrente. A ordem, a justiça e a retidão, tratam-se, por conseguinte, de princípios imutáveis, presentes desde sempre na constituição do cosmos egípcio.

O que se pretende atentar é, primeiramente, para o lugar que a deusa Maat ocupou na cosmogonia egípcia, que se tratou nada menos que, o próprio princípio encarnado da ordem regente do cosmos, ou seja, sua própria condição de sua existência e de seu funcionamento. Consequentemente, como princípio que rege e perpassa todos os elementos constituintes da natureza, ele se encontrou na base de toda estruturação política e social do império faraônico, conferindo governabilidade ao monarca, além de reger o comportamento individual do homem egípcio, pois, logicamente, foi a medida ética que orientou a conduta moral de seu comportamento. $\mathrm{O}$ egípcio não precisava obter essa energia de harmonia, pois ela não deve ser compreendida como algo externalizado da criação. A deusa é inerente a toda a natureza. Bastava-se, então, colocar-se em harmonia com ela (por si só um princípio absoluto, imutável), ou como os próprios egípcios diziam: "estar em Maat". Portanto, essa energia deveria ser mantida e renovada diariamente através do zelo pelas coisas religiosas, espirituais e políticas (rituais diários, ensinamentos de cunho moral, o zelo político do faraó para com o seu povo). 
No que diz respeito à Maat como princípio capaz de conferir coesão social, podemos vê-la manifestada por intermédio da figura do faraó, cujo papel consistia, antes de tudo, em zelar pela manutenção do equilíbrio Estado/Sociedade e Estado/Natureza. Sendo assim, o faraó era o representante máximo da humanidade, e por ela respondia perante os deuses: "A luz do céu se põe em harmonia com o Faraó/Para o Faraó, ela concilia a dualidade na harmonia/Para o Faraó, a obscuridade se põe em harmonia/A harmonia universal é o que é trazido ao Faraó/Ela é aquilo que ele vê e que ele ouve/A harmonia universal o precede e o acompanha./A harmonia universal lhe pertence." (Conto do homem do oásis).

A manutenção ou o restabelecimento da ordem sobre a injustiça significa que, a cada ascensão de um faraó ao trono do Egito, a ordem estava (ou deveria estar) assegurada, com a renovação desse pacto de governabilidade. Vejamos o trecho do rito de ascensão ao trono, proferido pela rainha Hat-Shep-Sut (XVIII Dinastia - aprox. 1580 a.C.), no qual ela diz ter se colocado em harmonia com a deusa Maat.

"Eu dei o máximo de valor à Regra (Maat).

Que o princípio divino o ama,

Eu sei que ele vive dela.

Ela é igualmente теи pão

Eu bebo seu orvalho,

Eu formo com ela um só ser.

Maat, a ordem social e perfeita,

Tanto da natureza como da sociedade,

Foi restabelecida como triunfo sobre a injustiça."

Para finalizar, vejamos como Maat atuava no plano moral e espiritual na formação cultural do homem egípcio. Maat pode ser compreendida, em termos de ordem mais pragmática, como um código de ética que deveria regulamentar o comportamento do homem egípcio, a fim de que finda a sua existência, o morto, perante um tribunal de deuses, dentre eles a deusa em questão, estivesse preparado para responder a uma série de questionamentos, cujo objetivo consistia em verificar sua retidão moral. $\mathrm{O}$ teor de tais máximas morais, não deve ser confundido com o caráter dogmático, que a ética assume em algumas religiões modernas. Obviamente, na construção histórica da sociedade, alguns ensinamentos, tomados de sábios e faraós, foram transmitidos de geração para geração, como os de Ptah-Hotep ${ }^{3}$, que

\footnotetext{
${ }^{3}$ O Ensinamento de Ptah-hotep é um texto do Antigo Egipto cujo autoria é atribuída a Ptah-

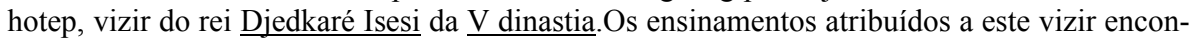
tram-se registados de forma completa no Papiro Prisse (assim chamado devido ao egiptólogo
} 
veremos logo abaixo. Vale ressaltar que, segundo o entendimento egípcio, cada homem deveria agir de acordo com o que dizia o seu próprio coração. Para tanto, o indivíduo necessitava estar sempre em harmonia com o órgão que representava a leveza da retidão cósmica. Maat, tratava-se de um princípio imutável inscrito no coração dos homens desde a criação. Se opor à ele, significava desarmonia, e consequentemente caos e sofrimento.

"Se encontrares um contendor em seu (melhor) momento, um homem humilde que não seja um teu igual, não o ataques por ser fraco. Deixa-o em paz, ele se refutará a si mesmo. Não lhe respondas

para aliviar teu coração, não laves teu coração contra teu oponente. Desprezível é aquele que humilha um homem humilde, (embora) cada um aja segundo seu coração".

No âmbito da espiritualidade individualizada, a deusa Maat, constitui o corpo de deuses ou leis cósmicas com as quais os homens deveriam prestar contas, após a sua jornada terrena. Para exemplificar essa questão, veremos um trecho extraído do Livro para Sair à $\mathrm{Luz}^{4}$, que corresponde à terceira região do Tuat, ou seja, local onde o morto deveria prestar contas de seu comportamento enquanto vivo, perante os deuses do panteão egípcio. Esta terceira região, ou terceira câmara, era denominada Câmara de Maat, lugar em que o morto era julgado perante um tribunal constituído de 42 deuses, dentre eles o deus Osíris $^{5}$, tendo o seu próprio coração pesado em uma balança, que simbolizava a deusa Maat. Para ser aprovado em seu julgamento, o morto teria que confessar ao deus Osíris, todos os bons e maus

francês Émile Prisse d'Avennes, que o encontrou na necrópole de Tebas no século XIX), datado do Império Médio (c. de 1900 a.C.) e que se encontra na Biblioteca Nacional de França. Há ainda mais dois papiros que possuem fragmentos do texto e que se encontram no Museu Britânico, datando do Império Médio e do Império Novo respectivamente; para além disso, a tábua Carnavon I no Museu Egípcio do Cairo possui igualmente um fragmento. Segundo o texto, Ptah-hotep, já de idade avançada, solicita ao rei a possibilidade de retirar-se do cargo. Ptah-hotep solicita igualmente que o seu filho o substitua, algo habitual na sociedade egípcia, onde se espera que o filho seguisse a profissão do pai. O rei aceita a proposta de Ptahhotep, mas este deve transmitir os seus conhecimentos sobre a vida ao filho, o que funcionará como uma espécie de testamento moral. O texto divide-se num prólogo (no qual Ptah-hotep se apresenta perante o rei pedindo a sua reforma), nos ensinamentos (trinta e sete máximas) e num epílogo.

${ }^{4}$ Nova denominação dada ao "Livro dos Mortos". Tal obra consiste na jornada em que o morto realiza ao mundo do deus Osíris, onde deve atravessar um conjunto de catorze regiões - designadas Tuat -, cada uma com uma provação específica, a fim de que possa novamente renascer, fundindo-se a essência do deus criador, completando, assim, seu ciclo de existência no universo.

${ }^{5}$ Representa no panteão egípcio a força criativa que liga à essência humana à essência do deus criador. Representa no tribunal dos deuses, o que o faraó representa para o seu povo. tribunal dos deuses, o que o faraó representa para o seu povo. 
atos que cometera em relação aos seus semelhantes, a natureza, e as leis cósmicas, durante a sua vida. Caso mentisse, o seu coração o denunciaria, pois o coração penderia mais que a pena de Maat, seu contrapeso. Sendo o morto reprovado, ele não alcançaria o mérito de avançar no seu caminho rumo ao reino da eternidade. Vejamos alguns trechos em que o morto se refere ao deus Osíris:

“Homenagem a Ti, ó Grande Deus, Senhor da Dupla Maat!

(...) Em verdade me coloquei em harmonização Contigo e trouxe

Maat em minha mente e em minha alma.

Por ti destruí a maldade e não fiz mal a seres humanos!

Não oprimi os membros da minha familia!

Não pratiquei o erro em lugar do direito e da verdade!

Não convivi com homens indignos!

Não exigi consideração especial!

Não apresentei meu nome para o enaltecimento!

Não privei de bens os oprimidos!

Não fiz alguém passar fome!

Não fiz alguém chorar!

Não causei dor a seres humanos e a animais!

Não adulterei os padrões de medida.'

Para concluir essa reflexão, retomarei o movimento de criação cósmica, mas especificamente no momento do "vir-a-ser", onde a criação se torna possível, pois todas as palavras proferidas pelo criador estão plenas do princípio da vida $(S h u)$ e da ordenação (Tefnut/Maat). O mecanismo de funcionamento da sociedade egípcia, calcava-se, portanto, na reprodução diária, momentânea do ato do "vir-a-ser", pois é exatamente nesse momento em que o movimento da criação se dá. E o lugar onde "o todo" se fragmenta, e que cuja organicidade é mantida graças ao princípio da deusa Maat, já que foge ao controle dos deuses quando o mundo é criado. A manutenção desse princípio é delegada, então, ao faraó (representante de todas as divindades nas terras do Egito - Espelho da Eternidade), aos sacerdotes (responsáveis pela reprodução diária de energia, através dos ritos) e de cada indivíduo comum, que deveriam submeter suas vidas diárias à retidão nascida do primeiro ato da criação.

Giselle Marques Camara

Mestre em História Social da Cultura pela PUC-Rio. Professora do Programa de Pós-graduação Latu Senso da Uerj Professora do Colégio de São Bento, de História Antiga da PUC-Rio 


\section{Bibliografia:}

Araújo, Emanuel. Escrito para a eternidade - literatura no Egito faraônico. Brasília, UNB. 2000.

Budge, E. A., Wallis. O Livro Egípcio dos mortos. São Paulo, Pensamento, 1999.

Castel, Elisa. Los sacerdotes del Antiguo Egipto. Madri, Alderabán, 1998

Clark, R. T. Rundle. Mitos e Símbolos do Antigo Egito. São Paulo, Hemus, 1992.

Donadoni, Sérgio (org.). O homem egípicio. Lisboa, Ed. Presença, 1990.

Faulkner, R.O. The Ancient Egypian - Book of the Dead. London, British Museum Press, 1996.

Hart, George. Mitos Egípcios. São Paulo, Editora Morais, 1992.

Jacq, Christian, A sabedoria viva do Antigo Egito. Rio de Janeiro, Bertran Brasil, 1999.

O mundo mágico do Antigo Egito. Rio de Janeiro, Bertran Brasil, 2001.

Johnson, Paul. A História Ilustrada do Egito Antigo. Rio de Janeiro, Ediouro, 2002.

Manzanares, César Vidal. Cuentos del Antiguo Egpito. Barcelona, Martínez Roca, 1998

Quirke, Stephen. The cult of the Ra: Sun-worship in Ancient Egypt. London, Thames and Hudson, 2001.

Shafer, Byron E (org.). As religiões no Egito Antigo - deuses, mitos e rituais domésticos. São Paulo, Nova Alexandria, 2002.

Shaw, Ian; Paul Nicholson. British Museum Dictionary of Ancient Egypt. London, British Museum Press, 1997.

Traunecker, Claude. Os deuses do Egito. Brasília, UNB, 1995.

Trigger, B. G; B. J. Kemp; D. O'Connor, A. B. Lloyd. Ancient Egypt - A social History. Cambridge, Cambridge University, 1999. 